\title{
INTEGRAÇÃO DAS TECNOLOGIAS DIGITAIS DE REDE AO CURRÍCULO: O PROTAGONISMO DOCENTE NO CICLO DA POLÍTICA
}

\author{
Ana Claudia Pereira RUBIO \\ Ozerina Victor de OLIVEIRA ${ }^{\text {ii }}$
}

\begin{abstract}
RESUMO
Este artigo problematiza a integração das Tecnologias Digitais de Rede (TDR) ao currículo escolar, com o propósito de identificar e expor o ciclo político de tal currículo e seus contextos, frente às políticas públicas vinculadas ao tema. Destaca-se o protagonismo docente na constituição de discursos que dão sustentação a essa integração em uma escola pública do estado de Mato Grosso. A pesquisa encontra-se teórica e metodologicamente orientanda pela compreensão de discurso de Laclau e Mouffe (1985), de currículo como discurso, de acordo com Lopes e Macedo (2011), e de ciclo de política, conforme Ball (1994). Em decorrência dessas escolhas, foram realizados estudos bibliográfico e documental e coleta de dados em campo. Para a coleta, recorreu-se a entrevistas com nove professores que atuam em um dos ciclos dos anos finais do Ensino Fundamental de uma escola pública e a observação participante em suas aulas. Considerando o movimento cíclico entre os contextos da política de currículo em análise, constatou-se que é possível integrar as TDR ao currículo, de forma a reconhecê-las como prática social e realizá-las, mesmo que provisoriamente, quando há protagonismo dos atores em questão. Além disso, percebeu-se que as TDR configuram mediações pedagógicas entre a vida de docentes e de discentes.
\end{abstract}

PALAVRAS-CHAVE: Tecnologias Digitais de Rede; Currículo do Ensino Fundamental; Protagonismo docente.

\section{INTEGRATION OF DIGITAL NETWORK TECHNOLOGIES INTO THE CURRICULUM: THE LEADING ROLE OF TEACHERS IN THE POLICY CYCLE}

\begin{abstract}
This article discusses the integration of Digital Network Technologies (DNT) in the school curriculum, with the aim of identifying and exposing the policy cycle of such curriculum and its contexts, in face of public policies related to the issue. We highlight the leading role of teachers in the constitution of discourses which support this integration in a public school in the State of Mato Grosso, Brazil. The research is theoretically and methodologically guided by the understanding of discourse drawn from

\footnotetext{
${ }^{\text {i } M e s t r a d o ~ e m ~ E d u c a c ̧ a ̃ o ~ p e l a ~ U n i v e r s i d a d e ~ F e d e r a l ~ d e ~ M a t o ~ G r o s s o, ~ n a ~ l i n h a ~ d e ~ p e s q u i s a ~ O r g a n i z a c ̧ a ̃ o ~ E s c o l a r, ~}$ Formação e Práticas Pedagógicas; e no Grupo Políticas Contemporâneas de Currículo e Formação Docente. Atualmente é Supervisora Técnica de Editoração e Normatização Gráfica e Membro do Conselho Editorial na Editora da Universidade Federal de Mato Grosso. E-mail: anaclaudiarubio@ yahoo.com.br.

ii Doutorado em Educação pela Universidade do Estado do Rio de Janeiro (2006); estágio pós-doutoral em Currículo da Educação do campo pela Universidade do Estado de Mato Grosso. Atualmente, é professora associada da Universidade Federal de Mato Grosso, nos cursos de Mestrado e Doutorado do Programa de PósGraduação em Educação, e é Pró-reitora de Ensino de Pós-Graduação nessa universidade. E-mail: ozerina@ufmt.br.
} 
Laclau and Mouffe (1985), of curriculum as discourse, according to Lopes and Macedo (2011) and of policy cycle, according to Ball (1994). As a result of these choices, a bibliographic and documentary study as well as field data collection were conducted. For the data collection, we used interviews with nine teachers who work in one of the cycles of the final grades of Elementary School of a public institution and the observations of a participant in their classes. Considering the cyclical movement between the curriculum policy contexts under analysis, it was found that it is possible to integrate DNT into the curriculum, in order to recognize them as social practice and carry them out, even if provisionally, when there is the leading role of the teachers investigated. In addition, it was noticed that DNT configure pedagogical mediations between the life of teachers and students.

KEYWORDS: Digital Network Technologies; Elementary School curriculum; Teacher leading role.

\title{
INTEGRACIÓN DE LAS TECNOLOGÍAS DIGITALES DE RED AL CURRÍCULO: EL PROTAGONISMO DOCENTE EN EL CICLO DE LA POLÍTICA
}

\begin{abstract}
RESUMEN
Este artículo problematiza la integración de las Tecnologías Digitales de Red (TDR) al currículo escolar, con el propósito de identificar y exponer el ciclo político de tal currículo y sus contextos, frente a las políticas públicas vinculadas al tema. Se destaca el protagonismo docente en la constitución de discursos que sustentan esa integración en una escuela pública del estado de Mato Grosso, Brasil. La investigación se encuentra teórica y metodológicamente orientada por la comprensión del discurso de Laclau y Mouffe (1985), del currículo como discurso, de acuerdo con Lopes y Macedo (2011) y de ciclo de política según Ball (1994). En consecuencia de esas elecciones, fueron realizados estudio bibliográfico, documental y recolección de datos en el campo. Para la recolección se recurrió a entrevistas con nueve profesores que actúan en uno de los ciclos de los años finales de Educación Básica de una escuela pública y la observación participante en sus clases. Considerando el movimiento cíclico entre los contextos de la política de currículo en análisis, se constató que es posible integrar las TDR al currículo, reconociéndolas como práctica social, realizándose, aunque provisionalmente, cuando hay protagonismo de los actores en cuestión. Además, se percibió que las TDR configuran mediaciones pedagógicas entre la vida de docentes y discentes.
\end{abstract}

PALABRAS CLAVE: Tecnologías Digitales de Red; Currículo de Educación Básica; Protagonismo docente.

\section{INTRODUÇÃO}

As Tecnologias Digitais de Rede (TDR) estão presentes no cotidiano escolar, a partir da criação de políticas públicas de inclusão digital, sendo utilizadas pelos protagonistas centrais do currículo (docentes e discentes). No entanto, é possível perceber que não basta o uso de tal ferramenta de modo descontextualizado, uma vez que as TDR precisam estar inseridas no currículo de modo a ter seu uso potencializado por esses atores. 
Durante pesquisa acerca da temática (KENSKI, 2009; BUZATO, 2006; SILVA, 2011) e nos espaços educacionais que frequentamos, percebemos dificuldades encontradas por discentes e docentes em utilizar as TDR de modo substantivo. Desse modo, as TDR estão incorporadas às várias dimensões da vida social, mas continuam a desafiar os espaços escolares quanto à sua integração ao currículo.

Em levantamento bibliográfico para delimitação desta pesquisa no Banco de Teses da Coordenação de Aperfeiçoamento de Pessoal de Nível Superior (CAPES) e na Biblioteca Brasileira de Teses e Dissertações (BDTD), encontramos 11 publicações, sendo duas teses e nove dissertações, as quais abordavam as tecnologias no currículo da Educação Básica: Ipiranga (2006), Campos (2008), Santos (2010), Santos (2011), Albuquerque (2011), Ferreira (2012), Milani (2012), Sentanin (2012), Costa (2012), Kretzer (2013) e Castro (2015).

A partir desses pesquisadores, apreendemos - entre outras questões (SANTOS; RUBIO, 2015) - que as pesquisas sobre a temática em tela ainda são insuficientes para compreender as possibilidades das tecnologias na Educação Básica. Nelas predominam a responsabilização dos docentes por não haver integração das tecnologias ao currículo escolar, e, entre os argumentos, estava o de que eles não possuem formação para o uso das TDR. Observamos, ainda, que há pesquisas que negligenciam tais atores, de modo a não considerarem suas vozes em relação ao uso das TDR quando pesquisam suas práticas pedagógicas. Diante do exposto, tornou-se imperiosa a realização de pesquisa que evidenciasse posicionamentos de docentes em relação ao uso desse recurso em âmbito escolar, mais precisamente no que diz respeito ao currículo.

Nesse sentido, avançar frente aos limites de responsabilização e negligência, ouvindo os docentes, passa por perscrutarmos sobre suas práticas culturais no que concerne à temática em questão. O que foi feito sob a orientação das seguintes questões: Quais os sentidos e os significados mobilizados pelos docentes em relação à integração das TDR no currículo escolar? Quais as relações desses sentidos e desses significados com políticas públicas de inclusão digital no currículo do Ensino Fundamental? Que desdobramentos os sentidos e os significados imprimem ao currículo pesquisado?

A pesquisa ${ }^{1}$, desenvolvida com tais questões e que ora se apresenta, tem o intuito de identificar, problematizar e compreender discursos que circulam na política de currículo de uma escola pública do estado de Mato Grosso frente às políticas públicas de currículo para o uso das TDR, destacando argumentos que dão sustentação a integração entre ambas. 
Em termos teóricos, compreendemos o currículo como discurso, portanto configurado por práticas culturais e de significação (LOPES; MACEDO, 2011), assim como as TDR como prática social (BUZATO, 2006) e, ainda, construímos a noção de discurso a partir da assimilação que o campo do currículo no Brasil faz da Teoria do Discurso de Laclau e Mouffe (1985).

Consoante a esse referencial, optamos pela abordagem qualitativa da pesquisa educacional. Outra decisão potente foi pautarmo-nos no ciclo de políticas, pensado por Ball e Bowe (1992) e Ball (1994). A escolha pelo Ciclo de Políticas deu-se por esta ser uma abordagem que favorece interpretações complexas e não-lineares de políticas curriculares por meio de discursos, ajudando nas respostas às questões já levantadas aqui. O Ciclo de Políticas propõe, conforme Matheus (2013), a noção de circularidade, realizando a interconexão entre as dimensões e desfazendo fronteiras entre atores, âmbitos e níveis do social. Ainda sob os referenciais de Ball e Bowe (1992) e Ball (1994), recorremos a três contextos do ciclo da política para o desenvolvimento da pesquisa, a saber: o contexto de influência, entendido como arena onde os discursos políticos, em meio às relações de poder, orientam as produções de políticas; o contexto da produção dos textos, arena onde são produzidos os textos por atores em competição pela definição das políticas; e, por fim, o contexto da prática, que é o alvo para o qual todas as ações políticas convergem e também o ponto a partir do qual os demais contextos são pensados.

Aliando a compreensão de discurso e de ciclo de políticas, as pesquisas do campo do currículo têm se dedicado à compreensão da significação que o currículo tem recebido nos diferentes contextos de produção e também às hibridizações produzidas entre eles. Diante disso, não podemos restringir as formações discursivas e os atores políticos a uma única conjuntura, todos os envolvidos, nos diferentes contextos, estão em constante luta política pela definição dos sentidos que serão impressos ao currículo (MATHEUS, 2013). São os sentidos que vão sendo hegemonizados nessas arenas que configuram o processo de significação da política e, portanto, dos discursos de integração das TDR. Isso quer dizer que nos discursos dos atores, há lutas e disputas mesmo quando há fixação do que se defende por integração das TDR ao currículo.

As decisões teórico-metodológicas envolveram, além do estudo bibliográfico já enunciado, a realização de estudo documental (LÜDKE; ANDRÉ, 2011), entrevistas e 
observação participante (EZPELETA; ROCKWELL, 1986). A análise de documentos foi desenvolvida a partir de textos de âmbito nacional, a saber: Lei de Diretrizes e Bases da Educação Nacional (LDB), Plano Nacional de Ensino (PNE) e documentos do Programa Nacional de Tecnologia Educacional (ProInfo). Além destes, textos produzidos na escola: Projeto Político Pedagógico (PPP), plano de ensino dos professores, caderno de agendamento da sala de informática e da sala de vídeo.

A observação participante em aulas ocorreu de maio a outubro de 2016 - com interrupção de dois meses devido à greve nas escolas públicas estaduais -, e os dados dela decorrentes foram registrados no diário de campo. Realizamos a observação do trabalho dos docentes de modo intercalado, seis semanas em cada turma e os acompanhamos em diferentes espaços, como sala de aula, sala dos professores, sala de informática e sala de vídeo. Considerando-se a organização do currículo em ciclos, as entrevistas foram realizadas em janeiro de 2017, com nove professores de uma escola pública estadual localizada na região leste do município de Cuiabá, Mato Grosso, todos atuantes na $2^{\mathrm{a}}$ e $3^{\mathrm{a}}$ fases do $3^{\circ}$ Ciclo (turmas B e C). Ademais, as entrevistas foram gravadas em celular e em notebook, com posterior transcrição das falas dos professores.

Importa destacarmos que este estudo foi organizado em três seções: na primeira, apresentamos as noções orientadoras da pesquisa, como Tecnologia Digital de Rede, Discurso e Currículo; na segunda, expomos o ciclo percebido entre os contextos e os discursos de integração das TDR ao currículo; já, na terceira seção, apresentamos algumas conclusões da pesquisa, a saber: percebemos que a possibilidade de integração das TDR ao currículo está em reconhecê-las como prática social, que se realiza, mesmo que provisoriamente, em alguns momentos do ciclo da política, tendo os docentes como protagonistas centrais.

\section{NOÇÕES ORIENTADORAS DA PESQUISA: TDR, CURRÍCULO E DISCURSO}

Na tríade TDR como prática social, currículo e discurso, consideramos as contribuições do movimento de (re)conceptualização do currículo, que se entende decidir-se por compromissos sociais e políticos (SAUL, 1985). Tomadas essas decisões, elas passam a fazer sentido e assumem significados, mesmo que não concernentes aos valores que supostamente as fundamentaram. 
Consideramos também o pensamento pós-estruturalista do campo do currículo no Brasil, que assume como núcleo central de análise o saber e o poder, os quais se encontram "[...] atavicamente interligados na instituição do "mundo real"” (LOPES; MACEDO, 2011, p. 203). Este é reconhecido como radicalmente simbólico, pois “[...] seus sentidos são construídos pela linguagem, pelos sistemas de significação que nada mais são do que a própria cultura" (LOPES; MACEDO, 2011, p. 203). Ainda de acordo com as autoras, os sentidos são estabelecidos pela cultura, e o ato de atribuir significado é sempre um processo cultural e discursivo, uma vez que cultura e linguagem se confundem.

Desse modo, a cultura é, fundamentalmente, prática de significação. Ela se manifesta como forma de entender o mundo social e de torná-lo inteligível. Diz respeito, principalmente, à produção de sentido, circunstância na qual a vida social só pode ser compreendida por sua dimensão de prática de significação. Ela passa a ser reconhecida como arena de negociação de sentidos, que só podem ser criados dentro de um sistema de linguagem e de significações, o que se configura como uma prática social (SILVA, 2006). Nessa relação, a cultura será percebida em uma perspectiva mais ampla do que objeto de ensino ou como uma produção cotidiana do meio social. Ela será depreendida como aquilo que permite a significação (LOPES; MACEDO, 2011). Nesse sentido, a concepção de cultura é alterada radicalmente, ampliando abordagens sociológicas centradas na compreensão de cultura como campo de luta e conflito e deslocando a ênfase da abordagem epistemológica para os efeitos de verdade inerentes às práticas discursivas.

Relacionando significados de cultura e currículo, este, como outros campos e atividades, é todo cultural, pois as práticas de significação configuram parte inerente ao seu funcionamento e existência (SILVA, 2006; OLIVEIRA, 2008). Na interseção entre o social e o cultural, mediados pela linguagem, o currículo é entendido como "[...] uma prática de atribuir significados, um discurso que constrói sentidos [...]" (LOPES; MACEDO, 2011, p. 203). O currículo é, portanto, prática cultural.

Ao assumirmos essa noção como orientadora desta pesquisa,

[...] o entendimento do currículo como prática de significação, como criação ou enunciação de sentidos, torna inócua distinções como currículo formal, vivido, oculto. Qualquer manifestação do currículo, qualquer episódio curricular, é a mesma coisa: a produção de sentidos. Seja escrito, falado, velado, o currículo é um texto que tenta direcionar o 'leitor', mas que o faz apenas parcialmente (LOPES; MACEDO, 2011, p. 42). 
O caráter discursivo atinge todos os significantes em disputa e não é diferente com o termo tecnologia, uma vez que "[...] a palavra 'tecnologia' é usada a todo momento por pessoas das mais diversas qualificações e até com propósitos divergentes” (VIEIRA PINTO, 2005, p. 219). Para a pesquisa que apresentamos, compreendendo as TDR como aquelas conectadas em rede, que facilitam a troca e o acesso às informações, a saber: laptop, netbook, notebook, desktop, tablet e celulares (QUADROS, 2013). Compreendemos, ainda, que as ferramentas da informática, ao serem incorporadas pelas pessoas como práticas sociais, passam a produzir efeitos sobre estas (CASTELLS, 1999).

Sobretudo, as TDR configuram relações sociais e culturais, como também estão implicadas na construção, na distribuição, na valorização e na transformação do conhecimento e definem quem está incluído e quem não está (BUZATO, 2006; VIERA PINTO, 2005). Mesmo havendo a produção de desconectados ou excluídos, as TDR assinalam novas possibilidades de interagir, colaborar, representar e expressar identidades, há pouco restritas às elites culturais, acadêmicas e econômicas. É nesse contexto que situamos as Tecnologias Digitais de Rede no currículo escolar como prática social. Para além de instrumento, tais ferramentas são formas de pertencimento, pois operar com tecnologias é participar da própria constituição do social.

Prática social, por sua vez, está sendo delineada como um fazer intrínseco ao contexto histórico e social (WENGER, 1998 apud BRAZÃO, 2008), à existência de comunidades que se identificam mutuamente em determinado tipo ou conjunto de fazeres (BRAZÃO, 2008). Essas comunidades não podem ser impostas ou instituídas formalmente; elas se formam a partir de processos de identificação. O termo "prática" ressalta o caráter social e negociado da trajetória dos indivíduos; implicam ações cotidianas, compartilhadas entre os membros de um grupo social, carregadas de expectativas normativas, sentidos e significados que ultrapassam os objetivos imediatos orientadores das ações realizadas. Elas estão relacionadas à transmissão de valores, identidade e senso de pertencimento a uma comunidade (JUNQUEIRA, 2009). Tais práticas “[...] se repetem continuamente, tornando-se parte 'natural' das coisas, o que torna difícil localizar e compreender as razões de se constituírem como tal" (BOURDIEU apud MILLER; GOODNOW, 1995). Sendo construída por processos de significação, “[...] toda prática social tem um caráter discursivo, tem uma dimensão cultural” (FARIAS, 2014, p. 28). 
As práticas sociais são significadas pelos agentes sociais por meio do discurso. Isso quer dizer que, ao assumirmos tal abordagem, não estamos nos referindo apenas ao campo linguístico e textual, mas, sim, estamos considerando a produção de discursos na vida prática, em contexto de uso da linguagem (LACLAU, 2005 apud FARIAS; DIAS, 2013).

Para além da noção de cultura e de currículo, pesquisas no campo, sobre o assunto em questão, têm recorrido à Teoria do Discurso de Laclau como uma forma de ampliar a compreensão do Ciclo da Política de currículo, entendendo-o como prática discursiva e de significação (OLIVEIRA; RUBIO, 2015). Para Laclau e Mouffe (2004), toda prática é um discurso e todo discurso é uma prática. Nesse sentido, discurso é " [...] uma categoria que une palavras e ações" (MENDONÇA; RODRIGUES, 2014, p. 49), sendo construído por meio de práticas sociais no campo da discursividade (CUNHA, 2013). Ainda sobre a noção de discurso, Mendonça (2009) compreende que:

O discurso é efeito, ou resultado, de uma prática articulatória. A articulação é um jogo de diferenças, no sentido de que as mesmas constituem e são constituídas pela prática articulatória. Não há, segundo a teoria do discurso, uma essência pré-constitutiva nas relações sociais; é a própria prática discursiva que estabelece as características e os limites identitários (MENDONÇA, 2009, p. 168).

Na mesma perspectiva e de forma mais minuciosa, Cunha (2013) vem dizer que:

[...] essas práticas são significadas e ressignificadas pelos sujeitos nas relações que estabelecem em um determinado contexto social e histórico, imprimindo significados, os quais estão presentes e referendados em uma memória, a qual de alguma forma torna a ser falada. [Assim], o discurso é a prática articulatória, que joga com a interdição, e nesse processo deixa um 'resto' não articulado, que luta dentro do campo discursivo pela subversão do que já existe ao mesmo tempo em que busca a hegemonia dos sentidos (CUNHA, 2013, p. 270).

Assim, compreendemos os sentidos e os significados como constituintes do discurso, uma vez que este “[...] não está relacionado apenas à fala e/ou à escrita: envolve também a ação - e seus efeitos -, pois não há ação que não esteja imersa na significação" (ARAUJO, 2014, p. 212). As TDR, compreendidas como prática social, realizam-se como tal quando inseridas no cotidiano escolar, integradas ao currículo e presentes nas atividades docentes. Estas, por sua vez, só estarão inseridas, integradas e presentes se tiverem significado para a comunidade escolar. 
Diante desse cenário, o uso potente das TDR no currículo implica no reconhecimento, por parte dos docentes, de práticas significativas em seu uso e as faz presentes nas mediações pedagógicas. De acordo com Ortner (1994, p. 394 apud JUNQUEIRA, 2009, p. 14), “[...] a 'intencionalidade da ação' é um dos elementos fundantes de práticas significativas para os atores envolvidos no jogo social". Tal intencionalidade precisa estar presente na experiência dos professores ao desenvolverem atividades com as TDR, visto que são as intencionalidades e as finalidades, acordadas coletivamente entre docentes e discentes, que dão sentido ao uso dos recursos tecnológicos no currículo escolar.

Para que as TDR sejam, de fato, integradas ao currículo, torna-se indispensável a criação de uma cultura de uso, em que "[...] a tecnologia deve se tornar uma parte integral das funções da sala de aula, tão acessível quanto todas as outras" (LUCENA, 2006, p. 31). De acordo com Cysneiros (2003, p. 23), “[...] sem uso, não se cria necessidade de uso, ou seja, usuários não notam sua ausência porque as tecnologias não fazem parte da rotina da escola". O uso pedagógico das TDR na escola exige dos professores outra dinâmica de organização das aulas, com tarefas extras e atividades novas (CYSNEIROS, 2003).

Em suma, reconhecer as conexões entre cultura, discurso e currículo viabilizou-nos compreender este último como prática de significação e das TDR como prática social, tornando possível a visualização de sua integração ao currículo.

\section{CICLO DA POLÍTICA, ATORES E DISCURSOS DE INTEGRAÇÃO DAS TDR AO CURRÍCULO}

Ao relacionarmos os dados coletados na pesquisa, visualizamos o movimento e a interseção entre os diferentes contextos do ciclo da política em análise, bem como o próprio movimento do discurso de integração das TDR ao currículo. Dar visibilidade a esse movimento requer a exposição e a análise de dados coletados em documentos, na observação e nas entrevistas. Para tanto, apresentamos os atores envolvidos na pesquisa, assim como a delimitação espaço-temporal desta.

No recorte do nível do currículo a ser analisado, optamos por anos finais do Ensino Fundamental ( $2^{\mathrm{a}}$ e $3^{\mathrm{a}}$ fases do $\left.3^{\circ} \mathrm{Ciclo}\right)$, pois adolescentes apresentam intensivas práticas de uso das TDR. Já a definição da escola, nomeada para fins desta pesquisa como Escola Flor do 
Cerrado, ocorreu sob as seguintes condições: aceitar participar da pesquisa, ofertar as $2^{\mathrm{a}}$ e $3^{\mathrm{a}}$ fases do $3^{\circ}$ ciclo no mesmo turno de funcionamento e possuir sala de informática com computadores em funcionamento, com acesso à internet e aberta para uso. Quanto à definição dos atores participantes, deu-se a partir de levantamento dos docentes e aceite do convite feito a eles. Todos os docentes da $2^{a}$ fase do $3^{\circ}$ ciclo, turma $\mathrm{C}$, e da $3^{\mathrm{a}}$ Fase do $3^{\circ}$ ciclo, turma $\mathrm{B}$, concordaram em participar da pesquisa. A denominação dos docentes deu-se a partir de nomes fictícios escolhidos por eles.

Nessas turmas, observamos o trabalho e entrevistamos docentes atuantes nas disciplinas de Artes, Ciências, Geografia, História, Inglês, Matemática e Português. As disciplinas de Matemática e Ciências tiveram dois participantes diferentes, pois não eram os mesmos docentes que atuavam nas duas turmas.

Em se tratando da análise de documentos, consideramos aqueles que alcançam relevância nacional, tais como Lei de Diretrizes e Base - LDB (Lei N ${ }^{\circ}$ 9.394, de 20 de dezembro de 1996), Plano Nacional de Educação - PNE (Lei No 13.005, de 25 de junho de 2014) e Programa Nacional de Tecnologia Educacional - ProInfo (criado pelo Ministério da Educação em 1997 e reestruturado por meio do Decreto $\mathrm{N}^{\circ}$ 6.300, de 12 de dezembro de 2007). Além disso, recorremos aos documentos produzidos no âmbito escolar: Projeto Político Pedagógico (PPP) da escola (2014), plano de ensino dos professores (2016), caderno de agendamento da sala de informática (2016) e da sala de vídeo (2016). Em atenção ao recorte de pesquisa, abordamos, a partir desses documentos, apenas o que diz respeito ao Ensino Fundamental.

Iniciamos a exposição do ciclo da política pela LDB, por obter um lugar de destaque nas políticas públicas educacionais, por sua abrangência, e, sobretudo, pelos acordos nela firmados. Nela identificamos referência às TDR no segundo parágrafo do artigo 32, o qual trata do objetivo do Ensino Fundamental para a formação básica do cidadão, conforme segue: “O ensino fundamental obrigatório [...] terá por objetivo a formação básica do cidadão, mediante: [...] II - a compreensão do ambiente natural e social, do sistema político, da tecnologia [...].” (BRASIL, 1996, n.p., grifos nossos).

Pela característica do documento - estabelecer bases gerais para educação brasileira -, as tecnologias são abordadas de forma mais ampla, na perspectiva de assegurar aos alunos do Ensino Fundamental acesso aos instrumentos culturais disponíveis, de acordo com o momento histórico-social. Tal abordagem pode favorecer a atribuição de diferentes significados aos 
propósitos das TDR no currículo escolar. Discursivamente, o que se ganha em abrangência, perde-se em força.

No PNE, identificamos a presença das TDR em estratégias da meta 7, conforme segue:

Meta 7: fomentar a qualidade da educação básica em todas as etapas e modalidades [...] Estratégias: [...] 7.12) incentivar o desenvolvimento, selecionar, certificar e divulgar tecnologias educacionais para [...] ensino fundamental $[. .$.$] incentivar práticas pedagógicas inovadoras que assegurem a$ melhoria do fluxo escolar e a aprendizagem, assegurada a diversidade de métodos e propostas pedagógicas, com preferência para softwares livres e recursos educacionais abertos [...] (BRASIL, 2014, p. 4, grifos nossos).

7.15) universalizar [...] o acesso à rede mundial de computadores em banda larga de alta velocidade e triplicar [...] a relação computador/aluno (a) nas escolas da rede pública de educação básica, promovendo a utilização pedagógica das tecnologias da informação e da comunicação [...] (BRASIL, 2014, p. 4).

Por meio das estratégias do PNE, percebemos que o uso das tecnologias é abordado em diversas perspectivas: melhoria da aprendizagem de estudantes e da qualidade da educação; incentivo à inserção de softwares livres em práticas pedagógicas e universalização da Internet.

Já no documento do ProInfo (2007), identificamos a presença das TDR em questões relacionadas ao uso pedagógico das tecnologias nos seguintes excertos:

O ProInfo [...] promoverá o uso pedagógico das tecnologias de informação e comunicação nas redes públicas de educação básica (BRASIL, 2007, n.p., grifo nosso).

[...] promover o uso pedagógico das tecnologias de informação e comunicação nas escolas de educação básica das redes públicas de ensino urbanas e rurais; [...] fomentar a melhoria do processo de ensino e aprendizagem com o uso das tecnologias de informação e comunicação [...] (BRASIL, 2007, n.p., grifo nosso).

As redes de ensino deverão contemplar o uso das tecnologias de informação e comunicação nos projetos político-pedagógico das escolas beneficiadas para participarem do ProInfo (BRASIL, 2007, n.p., grifo nosso).

A ênfase dada às TDR no documento do ProInfo, assim como nos documentos da LDB e do PNE, ocorre em uma perspectiva pedagógica, na melhoria da qualidade da educação e da aprendizagem. Identificamos, ainda, no documento do ProInfo, orientação para inclusão das TDR no PPP das escolas. 
Os discursos construídos a respeito das TDR nos documentos de âmbito nacional configuram uma integração orientada para a prática pedagógica, como possibilidade para melhorar a qualidade do ensino e a aprendizagem dos estudantes. Em termos de formação discursiva, ganha força a especificação do tipo de tecnologia e seu direcionamento para a aprendizagem escolar e para a qualidade da educação escolar. Em suma, a análise dos textos da LDB, do PNE e do ProInfo possibilitou com que nós percebêssemos certa instrumentalização das TDR, uma vez que são compreendidas como recurso para melhorar a qualidade da educação e da aprendizagem.

No que diz respeito aos diferentes documentos produzidos pela escola, percebemos que, no PPP, as políticas públicas vêm sendo incorporadas e ressignificadas no contexto escolar. Nesse documento, o tópico referente ao Ensino Fundamental sugere que os alunos precisam aprender a utilizar distintas fontes de informação, assim como os recursos tecnológicos, conforme segue:

Objetivos do ensino fundamental: os alunos precisam [...] saber utilizar diferentes fontes de informação e recursos tecnológicos para adquirir e construir conhecimentos [...] (Projeto Político Pedagógico da Escola Flor do Cerrado, 2014, p. 56).

No excerto, percebemos que se atribui importância ao uso das TDR pelos alunos como forma de adquirir e construir conhecimentos. Nessa perspectiva, as atividades propostas a serem desenvolvidas a partir das TDR, nos espaços escolares, devem possibilitar aos discentes e docentes "[...] oportunidades de simular, praticar e vivenciar as mais diversas situações, possibilitando a elaboração de diferentes processos de aprendizagem, considerados a partir de uma perspectiva hipertextual" (ALBUQUERQUE, 2011, p. 23).

No tópico disciplinas e conteúdos do PPP, identificamos menção às TDR nas disciplinas de Ciências e de Língua Estrangeira. Em Ciências, as TDR aparecem como objetivo, conteúdo e orientação didática; em Língua Estrangeira, consta no objetivo.

Ciências naturais - orientações didáticas: [...] leitura de textos de variadas fontes: [...] artigos da internet, etc. (Projeto Político Pedagógico da Escola Flor do Cerrado, 2014, p. 99, grifo nosso).

Ciências da natureza - objetivo: [...] criar oportunidades para que o educando adquira um conjunto de conceitos, procedimentos e atitudes que subsidiem a interpretação do mundo científico e tecnológico atual [...]. Conteúdos: [...] tecnologia e sociedade (Projeto Político Pedagógico da Escola Flor do Cerrado, 2014, p. 106, grifo nosso). 
Língua estrangeira moderna - objetivo [...] o desenvolvimento de habilidades comunicativas [...] oportunizando um acesso mais igualitário [...] [no] mundo de tecnologia (Projeto Político Pedagógico da Escola Flor do Cerrado, 2014, p. 108, grifos nossos).

Nesses excertos, mesmo quando abordadas nas disciplinas, as TDR continuam sendo vistas como um meio para se atingir um fim. Desse modo, o uso das TDR é nomeado de instrumental e situado como prática conservadora, considerado "[...] basicamente como enfeites de técnicas tradicionais de ensino, dourando a pílula, tornando o ensino tradicional mais atraente" (CYSNEIROS, 1999, p. 21).

As TDR também aparecem como espaço no qual os conteúdos de história e cultura afrobrasileira e africana podem ser trabalhados:

Lei 10.639/03: [...] a educação das relações étnico-raciais [...] se desenvolverão no cotidiano das escolas [...] nos laboratórios [...] de informática [...] (Projeto Político Pedagógico da Escola Flor do Cerrado, 2014, p. 47, grifos nossos).

Ainda no PPP, as TDR fizeram-se presentes em um número considerável de tópicos. Esse dado nos remete ao pensamento de Rossari e Vosgerau (2016), que defendem a importância de incluir as TDR no PPP com o intuito de garantir ações contínuas e discussões que favoreçam seu uso no currículo escolar.

Passando aos documentos de nível específico, os planos de ensino dos professores, observamos que o uso das TDR também toma dimensão instrumental, salvo a disciplina de Ciências da $2^{\mathrm{a}}$ Fase do $3^{\circ} \mathrm{Ciclo}$, turma $\mathrm{C}$, que abordou, mesmo que parcialmente, as TDR como capacidade. Isso demonstra disputas de sentido para o uso das TDR no currículo escolar. Nesse sentido, entendemos que as TDR continuam sendo integradas nas práticas pedagógicas a partir de disciplinas isoladas e com práticas pouco inovadoras.

Um fator que nos chamou atenção em relação ao plano de aula dos docentes foi que muitos não fizeram menção às TDR em seu plano de ensino, mas as utilizaram na sala de informática, fato identificado nos registros do caderno de agendamento da sala de informática e sala de vídeo. Ao questionarmos os docentes sobre esse fato nas entrevistas, eles afirmaram que o plano é entregue muito no início do ano, o que faz com que não coloquem as TDR no plano por ainda não conhecerem a escola e, também, os alunos. No entanto, alegam que, quando começam as aulas, eles percebem que há TDR disponível na escola e fazem uso. Em termos do ciclo de política, o fato de as ações desenvolvidas na sala de aula pelos professores não 
constarem no plano de aula significa que as políticas de currículo são constantemente ressignificadas no contexto da prática, tomando novos direcionamentos.

No que tange ao caderno de agendamento da sala de informática e da sala de vídeo, percebemos que a primeira foi mais utilizada nas aulas com os anos finais do Ensino Fundamental. Importa ressaltarmos que, por um lado, os professores quase não recorreram o laboratório de informática com as turmas que estávamos acompanhando; por outro lado, notamos que a sala de vídeo foi mais utilizada nas aulas com os anos finais do Ensino Fundamental. Portanto, os professores que observamos recorreram mais a sala de vídeo do que a sala de informática.

Nessas aulas, predomina o uso de audiovisuais a partir de Datashow. Indagados sobre isso nas entrevistas, os professores argumentaram que os fatores que os levavam a optar pela sala de vídeo são: facilidade, comodidade e disciplina por parte dos alunos, já que nesse espaço os alunos não têm possibilidade de pesquisar outras coisas. Outro fator apontado pelos entrevistados para usarem mais a sala de vídeo do que a de informática é o controle do tempo, pois todos os alunos, ao mesmo tempo, fazem a mesma atividade. Alegam, ainda, que a infraestrutura da sala de informática é insuficiente.

De acordo com Ribeiro Junior (2011), a apropriação dos audiovisuais pelas escolas apresenta um dilema: de um lado, a dominação; do outro, a transformação. Considerando-se as entrevistas, identificamos que a dominação orienta o uso do Datashow em sala de aula e na sala de vídeo. Esta, no viés da dominação, faz do professor o detentor do conhecimento, pois acredita controlar o conteúdo a que os alunos estão tendo acesso. Já na sala de informática, parece ser mais difícil controlar o acesso dos alunos. Algo que não pode ser desprezado em relação ao uso da sala de vídeo é o trabalho coletivo, uma vez que, na sala de informática, o trabalho é individualizado - cada aluno, em seu computador, desenvolve suas atividades predominantemente de forma individualizada.

A partir da análise dos documentos produzidos pela escola, percebemos que, em seu conjunto, os discursos no PPP sobre a integração das TDR ao currículo tiveram as políticas nacionais como referência. Tal documento se refere às TDR como possibilidade para a melhoria da qualidade da educação, desde que integradas às práticas pedagógicas dos professores, que necessitam de formação para uso dessas tecnologias. Assim, o sentido das TDR que predomina no discurso do PPP também é de instrumentalização. 
A análise de documentos produzidos pela escola possibilitou-nos perceber que, no contexto da prática, essas políticas estão sendo (re)significadas e começa a surgir nova perspectiva de uso das TDR, como prática social. Também é nesse mesmo contexto que nos deparamos com a inserção das TDR como apêndice, não como parte estruturante do currículo. Exemplo disso é a preferência pelo uso da sala de vídeo em detrimento da sala de informática, uma vez que, na sala de vídeo, os professores se mantêm como detentores do conhecimento.

A configuração do contexto do texto da política de integração das TDR no currículo, por meio da análise dos diferentes documentos produzidos em âmbito nacional e produzidos no cotidiano da escola, leva-nos a crer que as políticas de currículo em TDR têm forte influência de políticas nacionais, hegemonizando-se o sentido das TDR como práticas pedagógicas, visando à melhoria da qualidade do ensino - sentido permeado por lutas em torno da significação das TDR como prática social.

Ao englobarmos a configuração do contexto da prática nessa análise e perscrutarmos o ciclo da política de currículo, passamos a expor a análise da observação participante e das entrevistas, momento que nos deparamos com novos sentidos das TDR no currículo da Escola Flor do Cerrado.

Observamos que os docentes têm utilizado mais as TDR em seus afazeres diários do que em suas atividades em sala de aula, daí entendidas como prática social. Durante todos os dias da observação participante, presenciamos ao menos um dos professores observados usando o smartphone, às vezes acessando Facebook e, em outras, WhatsApp. Presenciamos três professores, sendo duas participantes da pesquisa, com notebook nesse espaço. Eles usaram o equipamento para preencher o diário que é on-line e salvar atividades no pen drive. Os professores usaram demasiadamente a sala de informática para fazer hora-atividades, planejamento e preencher o diário on-line. O uso das TDR para tal finalidade também foi presenciado em sala de aula, onde a professora Joaquina usou o notebook no horário da aula para colocar um Trabalho de Conclusão de Curso (TCC) nas normas da Associação Brasileira de Normas Técnicas (ABNT).

Nas entrevistas, também identificamos o uso das TDR por professores nos afazeres cotidianos, momento no qual os entrevistados disseram usar as TDR no dia a dia para comunicar-se, buscar informações, por necessidade e como entretenimento, conforme segue: 
A gente quase não conversa na escola. [...]. É tudo postado no grupo. É tudo postado no e-mail. Então eu uso. Todo dia tem que tá olhando pra ver se tem alguma coisa. Pra ficar atualizado mesmo (Professora Maria das Graças, 2017, grifos nossos).

Questão da informação. Primeiro lugar. Segundo assunto é questão do lazer (Professor Carlos, 2017, grifos nossos).

Consideramos relevante trazer os sentidos das TDR nas práticas culturais dos professores, em seus afazeres cotidianos, uma vez que as pessoas passam a usá-las a partir de interesse próprio (BUZATO, 2008), e o uso cotidiano dessas tecnologias pode se mostrar como algo positivo nas práticas profissionais desses usuários, pois “[...] quando as mídias fazem parte da vida do sujeito e integram seu sistema de relações sociais junto às pessoas com as quais se relaciona, há uma forma de apropriação" (FANTIN, 2010, p. 11). Assim apropriadas, as TDR podem se inserir nas atividades em sala de aula, o que, por sua vez, poderá impulsionar sentidos de sua integração como prática social, formando um ciclo potente.

Mesmo assim, considerando que o currículo escolar é espaço de disputa por significações, percebemos que o sentido instrumental das TDR ainda predomina no currículo da Escola Flor do Cerrado. Chegamos a essa afirmação porque todas às vezes que os professores levaram o notebook para a sala de aula foi para copiar algo que estava salvo na memória do notebook e salvar no pen drive. Os professores faziam hora-atividade na sala de informática; entretanto, nunca usavam os computadores para fazer pesquisa, acabavam usando-os apenas para preencher os diários on-line. Já o celular foi utilizado pelos professores em sala de aula como relógio ou para gravar e também fotografar as apresentações dos alunos. No entanto, não presenciamos esse material sendo trabalhado ou apresentado para a turma.

Aliado ao sentido instrumental, o desenvolvimento de atividades pelos professores na sala de informática com as turmas de alunos parece estar condicionado ao bom comportamento deles: a professora Mulher Maravilha levou os alunos da $2^{\mathrm{a}}$ Fase do $3^{\circ}$ Ciclo da turma $\mathrm{C}$ à sala de informática para realizar pesquisa. Durante esse processo, a professora deixou os alunos ouvirem música nos fones de ouvido, mas ficou acordado que, se não fizessem a atividade proposta, eles guardariam os fones. Ao final da aula, como os alunos haviam tido um "bom comportamento" e realizado a atividade proposta, ela os deixou usar as redes sociais e jogar, agendando novamente a sala de informática.

Em outro momento, o professor Carlos nos disse que estávamos observando as piores salas da escola, pois, com aqueles alunos, não havia como fazer coisas diferentes e não daria 
nem para levá-los à sala de informática. Já a professora Joaquina, ao levar os alunos à sala de vídeo, também disse que tentava fazer algo diferente, mas aqueles alunos não se interessavam, não prestavam atenção, só conversavam. Acrescentou que estava pensando em levá-los novamente à sala de vídeo na aula seguinte, mas devido ao "mau comportamento", ela não os levaria mais. Nessa perspectiva, o uso das TDR parece ocorrer como uma forma de recompensa e não com o intuito de possibilitar o desenvolvimento da aprendizagem dos alunos de forma mais significativa, prazerosa e como parte de sua vida.

As potencialidades das TDR têm sido pouco exploradas pelos professores em sala de aula com seus alunos: houve casos em que as tecnologias, mais precisamente o celular, poderiam ter sido utilizadas para o desenvolvimento das atividades, mas os professores não permitiram que os alunos as utilizassem. Por exemplo, a professora Maria das Graças passou uma atividade de tradução para os alunos, mas não tinha dicionário para todos. Então, quem ficou sem dicionário tinha de esperar alguém terminar para pegá-lo e fazer a atividade. Uma aluna perguntou para a professora se podia usar o dicionário on-line no celular; no entanto, a professora disse que não. Houve outros professores que também proibiram o uso do celular para realização de atividades.

Durante as entrevistas lhes foi perguntado sobre o motivo da proibição e alegaram seguir a Lei Estadual № 10.232, de 29 de dezembro de 2014, que proíbe o uso do celular por alunos e professores nos horários de aula (MATO GROSSO, 2014). No entanto, essa Lei permite o uso do celular em atividades pedagógicas, o que não foi mencionado. Também teve professores que disseram que o celular não deveria ser usado em sala de aula, conforme consta nos excertos a seguir:

Ah, no meu entender assim, eu acho que tem uma regra que não pode usar o celular na sala de aula. Os alunos não podem usar [...] (Professora Souza, 2017, grifo nosso).

Então, eu já trabalhei em outra escola e eu trabalhava bastante com o celular, e os alunos eram mais incentivados. E aqui, por conta de ser proibido, de repente o diretor chega na sala e [...] o aluno está usando para outro fim, aí é o professor que responde (Professora Maria da Graças, 2017, grifos nossos).

O uso do celular em sala de aula tem gerado muita polêmica nos espaços escolares, o que tem levado professores a recorrerem à proibição dos aparelhos durante as aulas, chegando a ponto de alguns estados brasileiros criarem leis com essa finalidade. Acreditamos que tal 
coibição não seja o melhor caminho a seguir, pois o celular já está integrado às práticas culturais das pessoas; assim, a equipe pedagógica da escola deve perceber o seu uso "[...] como mais um recurso pedagógico disponível em sala de aula para aquisição de saberes" (SILVA; SANTOS, 2016, p. 149).

A utilização do celular em sala de aula possibilita realizar pesquisas na internet, fazer cálculos de forma mais rápida, formar memórias fotográficas das diversas atividades pedagógicas, registrar atividades, aprender a montar aplicativos para apresentações pedagógicas, entre outras possibilidades. Ele também tem sido apontado como aliado no ensino de disciplinas tidas como abstratas. Silva e Santos (2016, p. 160) apontam que “[...] essa tecnologia para aplicação nas disciplinas de geografia, física e problemas de matemática se tornaria uma situação concreta de visualização de situações onde a aprendizagem seria imediata por parte do discente". Considerar o celular no desenvolvimento de atividades em sala de aula é uma forma de acolher as práticas culturais dos jovens no currículo escolar, além de recorrer aos benefícios que essa tecnologia pode trazer para o processo pedagógico.

Entendemos que as TDR estão sendo integradas ao currículo escolar na Escola Flor do Cerrado de modo off-line, uma vez que, durante a observação participante, percebemos que os professores fazem pesquisas, veem vídeos na Internet, além de trazerem essas discussões para a sala de aula e para a sala dos professores. Por exemplo, a professora Mulher Maravilha pesquisou sobre os dois processos de impeachment ocorridos no Brasil e, desse modo, trouxe a discussão para debater com os alunos na sala de aula. A professora Joaquina levou os alunos para a sala de vídeo, para assistir a um documentário que ela havia baixado do Youtube e salvo no pen drive.

A partir do exposto, percebemos que os professores participantes da pesquisa estão se apropriando das TDR em suas práticas em sala de aula em modo off-line, pelo qual estes têm acesso a informações on-line e depois as retransmitem aos alunos, com o intuito de levantar discussões, assim como construir conhecimentos. Esse fato observado em relação ao uso das TDR a partir de práticas off-line também foi abordado por Facioli (2013) em sua dissertação. A autora aponta:

Muitos de nós, senão a maioria, têm em mente bons exemplos de conversas, seja no ambiente de trabalho ou em uma mesa de bar, conduzidas com base no que foi explicitado, visto, postado, curtido e comentado na rede. Eu mesma, em meu círculo de amigos, acadêmicos ou não, me vi inserida em conversas 
que começavam, muitas vezes, após comentários sobre postagens em redes sociais (FACIOLI, 2013, p. 74).

A partir desse excerto, podemos dizer que a perspectiva de relações construídas off-line pode ser considerada uma prática naturalizada em nossa sociedade e que vem sendo discutida por alguns autores, como Duque (2013) e Facioli (2013). Nesse sentido, Facioli (2013, p. 74) argumenta: "[...] é dado que existe uma porosidade das relações on-off: a internet fala da vida off e se estrutura com base na dinâmica da vida fora da rede, e a vida off fala da internet com a mesma ou maior intensidade". Assim, podemos dizer que as TDR estão integradas ao currículo da escola.

A partir das entrevistas, podemos dizer que tais tecnologias estão integradas ao currículo da escola, pois todos os professores atuam com as tecnologias digitais de modo off-line, buscando conteúdos para suas aulas. $\mathrm{Na}$ integração off-line, esses atores do currículo apropriam-se dos conteúdos a serem trabalhados em sala de aula de forma on-line e trabalham com eles junto aos seus alunos de forma off-line, como podemos observar nos excertos das entrevistas a seguir:

Eu preparo através de internet, dos sites importantes na minha área mesmo [...] (Professora Joaquina, 2017, grifo nosso).

Aí depende do conteúdo, por exemplo, quando eu fui utilizar a questão do impeachment da Dilma. Então, foi da internet [...] (Professora Mulher Maravilha, 2017, grifo nosso).

Então, tem certas coisas que eu acho que [a internet] ajudou muito [...] pra fazer pesquisa, $[\ldots]$ buscar atividades. Antigamente, a gente tinha que ficar com aquelas pilhas e pilhas de livros em casa. Para você buscar coisas diferentes. Hoje não, você vai no computador, você vai na internet, você tem maneiras e mais maneiras de fazer uma aula diferente [...]. (Professora Mônica, 2017, grifos nossos).

É a busca do conhecimento realmente. [...]. A única coisa que a gente utiliza mais é celular, que a gente fica mais próxima. Ultimamente, computador a gente vai deixando mais de lado. [...] Eu utilizo mais computador, mais mesmo pros diários eletrônicos. Assim, quando você vai buscar um vídeo, uma coisa mais interessante pros alunos (Mulher Maravilha, 2017, grifos nossos).

A partir dos sentidos e dos significados mobilizados pelos professores para integrarem as TDR a suas práticas em sala de aula, percebemos dois significados mobilizadores: um é em prol da aprendizagem do professor e o outro do aluno. Assim, acreditamos que a integração das TDR às práticas pedagógicas, mesmo off-line, podem estar acontecendo de modo colaborativo 
entre professores e alunos, para que a produção de conhecimento perpasse os contextos de ambos os agentes, de modo que se formariam mutuamente.

A partir das análises, acreditamos que o audiovisual precisa ser percebido nos espaços escolares "[...] como um processo dinâmico que transforma a própria prática pedagógica, sintonizando escola, educadores e educandos com a sociedade da informação audiovisual de forma crítica, criativa e humanizadora" (RIBEIRO JUNIOR, 2011, n.p.). Nessa perspectiva, os alunos seriam “[...] capazes não somente de [...] [compreender esses recursos] em profundidade, mas também de expressar-se por intermédio deles [...]" (FERRÉS, 1996 apud RIBEIRO JUNIOR, 2011, n.p.). Nesse sentido, a integração das TDR às atividades em sala de aula ocorre a partir da perspectiva da transformação.

\section{TECENDO CONSIDERAÇÕES}

Ao levarmos em conta a importância do contexto do texto e do contexto da prática para a compreensão do movimento das políticas de currículo, apresentamos os movimentos da política de currículo em TDR em uma escola pública a partir de documentos, originários do contexto do texto e das entrevistas e das observações, originárias do contexto da prática.

Ao problematizarmos os discursos produzidos pelas políticas de âmbito nacional (LDB $\mathrm{N}^{\circ}$ 9.394/1996, PNE - Lei $\mathrm{N}^{\circ}$ 13.005/2014) e documento do PROINFO (Decreto $\mathrm{N}^{\circ}$ 6.300/2007) para o uso das TDR, identificamos sua influência no texto do PPP da Escola Flor do Cerrado, uma vez que a construção das políticas recebe influência de diferentes grupos em busca de hegemonia da política. Também percebemos que os discursos dos documentos supracitados que predominaram na escola estavam relacionados ao uso das TDR como práticas pedagógicas e sua possibilidade para a melhoria da qualidade do ensino e da aprendizagem.

Considerando que o contexto da prática é arena de realização e de ressignificação das políticas, percebemos que, na Escola Flor do Cerrado, mesmo que ainda de maneira tímida, há uma iniciativa de integrar as TDR como prática social, fato percebido por meio das entrevistas e, também, do plano anual dos professores. A integração das TDR como prática social ao currículo escolar possibilita realizar práticas mais significativas de ensino e de aprendizagem, tanto para os alunos quanto para os professores, assim como ressignificar a integração das TDR ao currículo, que vem ocorrendo na escola de modo instrumental. 
A partir da análise dos contextos apresentados, percebemos ainda que a política de currículo em TDR em curso na Escola Flor do Cerrado demanda formação dos professores no que diz respeito à integração dos recursos tecnológicos ao currículo escolar, mas acreditamos que, além da formação, é necessário o reconhecimento das TDR como prática social, fato que poderia possibilitar aos alunos e aos professores desenvolverem novas aprendizados nos espaços escolares, como a elaboração de trabalhos colaborativos, deixando de ser meros receptores de informação e assumindo o protagonismo de produtores no contexto escolar.

No ciclo da política, o discurso configurador dos sentidos e dos significados mobilizados pelos professores para integrarem as TDR a suas práticas em sala de aula, são: a realização de pesquisas, a busca por conhecimento e informação e o aumento do interesse dos alunos.

Os professores da Escola Flor do Cerrado têm se apropriado das tecnologias digitais no espaço escolar de quatro formas: instrumental, disciplinar, off-line e prática social. Em práticas desenvolvidas com TDR de forma instrumental, esta é utilizada como recurso. Ao utilizá-las de forma disciplinar, são executadas de modo isolado, em horário e espaço determinado pelo professor. Durante as práticas desenvolvidas de modo off-line, os professores fazem pesquisas na Internet para planejarem as suas aulas, acrescentando conteúdos nas discussões com os alunos. Desse modo, as buscas/pesquisas não são feitas em tempo real.

Os processos de construção de políticas não são neutros, pois sempre há falas que geram embates antagônicos em torno da hegemonização de significados. Assim, ao compreendermos tal fato, percebemos que, na política de currículo de tecnologias digitais na Escola Flor do Cerrado, há o predomínio de discursos em prol da integração das TDR ao currículo escolar, assim como há outros que dificultam tal integração.

Ao final das análises, acreditamos que o reconhecimento das TDR como prática social e seu uso na perspectiva da transformação possibilitaria o desenvolvimento de métodos mais significativos para alunos e professores nos espaços escolares, assim como poderia torná-los mais criativos, interativos, colaborativos, motivados e, sobretudo, autorais.

\section{REFERÊNCIAS}

ALBUQUERQUE, Aparecida Maria Costa de. Integração do laboratório de informática ao currículo: práticas numa escola municipal de Fortaleza. 2011. Orientador: José Aires de Castro Filho. Dissertação (Mestrado em Educação Brasileira) - Universidade Federal do Ceará, Fortaleza, 2011. 
ARAUJO, Jair Jonko. A complexa construção de sentidos no cotidiano escolar: o caso da área de design do campus Pelotas do Instituto Federal Sul-rio-grandense. Revista Currículo sem Fronteiras, v. 14, n. 3, p. 208-229, set./dez. 2014.

BALL, Stephen John. Education reform: a critical and post-structural approach. Buckingham: Open University Press, 1994.

BALL, Stephen John; BOWE, Richard. Subject departments and the "implementation" of National Curriculum policy: an overview of the issues. Journal of Curriculum Studies, v. 24, n. 2, p. 97-115, 1992.

BRASIL. Decreto N$^{\circ}$ 6.300, de 12 de dezembro de 2007. Dispõe sobre o Programa Nacional de Tecnologia Educacional - ProInfo. Brasília: Presidência da República, Casa Civil, Subchefia para Assuntos Jurídicos, [2007]. Disponível em: http://www.planalto.gov.br/ccivil_03/_Ato2007-2010/2007/Decreto/D6300.htm. Acesso em: 20 jan. 2020.

BRASIL. Lei No 9.394, de 20 de dezembro de 1996. Estabelece as diretrizes e bases da educação nacional. Brasília: Presidência da República, Casa Civil, Subchefia para Assuntos Jurídicos, [1996]. Disponível em: http://www.planalto.gov.br/ccivil_03/leis/19394.htm. Acesso em: 20 jan. 2020.

BRASIL. Lei No 13.005, de 25 de junho de 2014. Aprova o Plano Nacional de Educação PNE e dá outras providências. Diário Oficial da União: seção 1, Brasília, DF, n. 120-A, edição extra, p. 1-7, 26 jun. 2014.

BRAZÃO, Paulo. A prática social, a tecnologia e a construção do currículo. In: MENDONÇA, A.; BENTO, A. (Orgs.). Educação em tempo de mudança. Funchal: CIE Uma, 2008. p. 107-113.

BUZATO, Marcelo El Khouri. Letramentos digitais e formação de professores. Portal Educarede, São Paulo, 2006. Disponível em: https://www.academia.edu/1540437/Letramentos_Digitais_e_Forma\%C3\%A7\%C3\%A3o_de _Professores. Acesso em: 5 set. 2015.

BUZATO, Marcelo El Khouri. Inclusão digital como invenção do quotidiano: um estudo de caso. Revista Brasileira de Educação, Rio de Janeiro, v. 13, n. 38, p. 325-342, maio/ago. 2008.

CAMPOS, Flavio Rodrigues. Diálogo entre Paulo Freire e Seymour Papert: a prática educativa e as Tecnologias Digitais de Informação e Comunicação. 2008. Orientadora: Maria Lúcia Marcondes Carvalho Vasconcelos. Tese (Doutorado em Letras) - Universidade Presbiteriana Mackenzie, São Paulo, 2008.

CASTELLS, Manuel. A sociedade em rede. São Paulo: Paz e Terra, 1999. 
CASTRO, Márcia Ferreira de. A organização escolar para a integração das Novas Tecnologias de Informação e Comunicação ao processo de ensino e aprendizagem. 2015. Orientador: Sebastião de Souza Lemes. Dissertação (Mestrado em Educação Escolar) Faculdade de Ciências e Letras, Universidade Estadual Paulista, Araraquara, 2015.

COSTA, Rosana Soares Gomes. Educação inclusiva digital: novas ferramentas curriculares para a aprendizagem na educação básica. 2012. Orientadora: Sandra Vidal Nogueira. Dissertação (Mestrado em Teologia) -Escola Superior de Teologia, São Leopoldo, 2012.

CUNHA, Kátia Silva. A teoria do discurso como abordagem teórica e metodológica no campo das políticas públicas em educação. Revista Estudos Políticos, Niterói, v. 2. n. 7, p. 257-276, 2013.

CYSNEIROS, Paulo Gileno. Gestão escolar: parâmetros curriculares e novas tecnologias na escola. In: RAMOS, Edla Maria Faust; ROSATELLI, Marta Costa; WAZLAWICK, Raul Sidney (Orgs.). Informática na escola: um olhar multidisciplinar. Fortaleza: Editora da UFC, 2003. p. 11-24.

DUQUE, Tiago. Gêneros incríveis: identificação, diferenciação e reconhecimento no ato de passar por. 2013. Orientadora: Karla Adriana Martins Bessa. Tese (Doutorado em Ciências Sociais) - Instituto de Filosofia e Ciências Sociais, Universidade Estadual de Campinas, Campinas, 2013.

EZPELETA, Justa; ROCKWELL, Elsie. Pesquisa participante. São Paulo: Cortez, 1986.

FACIOLI, Lara Roberta Rodrigues. Conectadas: uma análise de práticas de ajuda mútua feminina na era das mídias digitais. 2013. Orientador: Richard Miskolci. Dissertação (Mestrado em Sociologia) - Universidade Federal de São Carlos, São Carlos, 2013.

FANTIN, Monica. Dos consumos culturais aos usos das mídias e tecnologias na prática docente. Revista Motrivivência, Florianópolis, ano XXII, n. 34, p. 12-24, jun. 2010.

FARIAS, Cardoso Lívia. Discursos sobre o uso das tecnologias de informação e comunicação (TIC) na educação: uma análise das políticas de currículo Iberoamericanas. 2014. Orientadora: Rosanne Evangelista Dias. Dissertação (Mestrado em Educação) Faculdade de Educação, Universidade Federal do Rio de Janeiro, Rio de Janeiro, 2014.

FARIAS, Cardoso Lívia; DIAS, Rosanne Evangelista. Discursos sobre o uso das TIC na educação em documentos ibero-americanos. Linhas, Florianópolis, v. 14, p. 83- 104, 2013.

FERREIRA, Jalmelice da Luz. Os usos das tecnologias de comunicação e informação no desenvolvimento da leitura e escrita no Ensino Fundamental. 2012. Orientador: José de Sousa Miguel Lopes. Dissertação (Mestrado em Educação) - Faculdade de Educação, Universidade do Estado de Minas Gerais, Belo Horizonte, 2012.

IPIRANGA, Lucilia Collares. Projetos cooperativos de aprendizagem mediados por tecnologia de comunicação digital na promoção da aprendência. 2006. Orientador: Edel 
Ern. Dissertação (Mestrado em Educação) - Centro de Ciências da Educação, Universidade Federal de Santa Catarina, Florianópolis, 2006.

JUNQUEIRA, Eduardo Santos. Como alunos percebem as tecnologias digitais no laboratório da escola: problemas de aprendizagem e os caminhos apontados pela teoria da prática. UFC: Editora Universidade Federal do Ceará, 2009.

KENSKI, Vani Moreira. Tecnologias e ensino presencial e a distância. 7. ed. Campinas: Papirus, 2009.

KRETZER, Suleica Fernanda Biesdorf. A prática educativa em um processo de incorporação das tecnologias móveis na escola. 2013. Orientadora: Monica Fantin. Dissertação (Mestrado em Educação) - Universidade Federal de Santa Catarina, Florianópolis, 2013.

LACLAU, Ernesto; MOUFFE, Chantal. Hegemony and socialist strategy: towards a radical democratic. London: Verso, 1985.

LACLAU, Ernesto; MOUFFE, Chantal. Hegemonía y estrategia socialista: hacia una radicalización de la democracia. Buenos Aires: Fondo de Cultura Económica de Argentina, 2004.

LOPES, Alice Casimiro; MACEDO, Elizabeth. Teorias de currículo. São Paulo: Cortez, 2011.

LUCENA, Marisa. Liderança, gestão e tecnologia: para melhoria da educação no Brasil. In: ALMEIDA, Fernando José de; ALMEIDA, Maria Elizabeth B. B. de (Coords.). Integração das tecnologias na gestão escolar do livro. São Paulo: Microsoft/PUC-SP, 2006. p. 27-31.

LÜDKE, Menga; ANDRÉ, Marli Eliza Dalmazo. Pesquisa em educação: abordagens qualitativas. São Paulo: EPU, 2011.

MATHEUS, Danielle dos Santos. O discurso da educação de qualidade nas políticas de currículo. 2013. Orientadora: Alice Ribeiro Casimiro Lopes. Tese (Doutorado em Educação) - Faculdade de Educação, Universidade do Estado do Rio de Janeiro, Rio de Janeiro, 2013.

MATO GROSSO. Lei $\mathbf{N}^{\mathbf{0}} \mathbf{1 0 . 2 3 2}$, de 29 de dezembro de 2014. Torna defeso, para fins não pedagógicos, o uso de aparelhos eletrônicos em sala de aula do ensino fundamental e médio do Estado de Mato Grosso. Cuiabá: Assembleia Legislativa do Estado de Mato Grosso, [2014]. Disponível em:

http://www2.seduc.mt.gov.br/documents/8501214/0/29.12.14+Lei+10232+Torna+defeso+o+ uso+de+aparelhos+eletr\%C3\%B4nicos+em+sala+de+aula.pdf/d0fe8b1f-8b21-8e5f-0730abfd59b01 94f. Acesso em: 20 jan. 2020.

MENDONÇA, Daniel. Como olhar "o político" a partir da teoria do discurso. Revista Brasileira de Ciência Política, Brasília, n. 1, p. 153-169, jan./jun. 2009. 
MENDONÇA, Daniel; RODRIGUES, Léo Peixoto. Do estruturalismo ao pós-estruturalismo: entre fundamentar e pós-fundamentar. In: MENDONÇA, Daniel; RODRIGUES, Léo Peixoto. Pós-estruturalismo e Teoria do Discurso: em torno de Ernesto Laclau. 2. ed. Porto Alegre: EdiPUCRS, 2014. p. 27-45.

MILANI, Débora Raquel da Costa. Contemporaneidade e educações: mídias digitais nas culturas juvenis. 2012. Orientadora: Sueli Aparecida Itman Monteiro. Tese (Doutorado em Educação Escolar) - Faculdade de Ciências e Letras, Universidade Estadual Paulista, Araraquara, 2012.

MILLER, Peggy Jo; GOODNOW, Jacqueline Jarrett. Cultural practices as contexts for development. San Francisco: Jossey-Bass Publishers, 1995.

OLIVEIRA, Ozerina Victor de. Movimento comutativo da política de currículo: o caso da Escola Sarã. Revista de Educação Pública, Cuiabá, v. 17, n. 33, p. 13-24, jan./abr. 2008.

OLIVEIRA, Ozerina Victor de; RUBIO, Ana Claudia Pereira. Campo do currículo e estudos de Teoria do Discurso de Laclau e Mouffe: apropriações. In: SIMPÓSIO PÓS ESTRUTURALISMO E TEORIA SOCIAL: O LEGADO TRANSDISCIPLINAR DE ERNESTO LACLAU, 1., 2015, Pelotas. Anais eletrônicos [...]. Pelotas: UFPel, 2015. Disponível em: https://wp.ufpel.edu.br/legadolaclau/files/2015/07/ozerina-de-oliveira.pdf. Acesso em: 25 jan. 2020.

QUADROS, Amanda Maciel de. Práticas educativas e tecnologias digitais de rede: novidade ou inovação? 2013. Orientadora: Tania Beatriz Iwaszko Marques. Dissertação (Mestrado em Educação) - Faculdade de Educação, Universidade Federal do Rio Grande do Sul, Porto Alegre, 2013.

RIBEIRO JUNIOR, Djalma. O Audiovisual na Escola: dominação ou transformação. Revista Universitária do Audiovisual, 15 mar. 2011. Disponível em: http://www.rua.ufscar.br/oaudiovisual-na-escola-dominacao-ou-transformacao/. Acesso em: 20 jan. 2020.

ROSSARI, Marilusa; VOSGERAU, Dilmeire Sant'Anna Ramos. O Projeto Político Pedagógico e a integração das tecnologias. In: SÁ, Ricardo Antunes de (Org.). Tecnologias e mídias digitais na escola contemporânea: questões teóricas e práticas. Curitiba: Appris, 2016. p. 37-68.

SANTOS, Cláudia Tavares Barbosa. O portal do professor e projetos de trabalho: uma proposta de construção de um ambiente de aprendizagem matemática no Ensino Fundamental. 2011. Orientador: Klaus Schlünzen Júnior. Dissertação (Mestrado em Educação) - Faculdade de Ciências e Tecnologia, Universidade Estadual Paulista, Presidente Prudente, 2011.

SANTOS, Jocilene Barboza dos; RUBIO, Ana Claudia Pereira. Políticas de currículo e tecnologias digitais de rede. In: COLÓQUIO INTERNACIONAL DE POLÍTICAS E PRÁTICAS CURRICULARES, 7., 2015. Anais [...]. João Pessoa: UFPB, 2015. p. 31793192. 
SANTOS, Maximiliana Batista Ferraz dos. Laptops na escola: mudanças e permanências no currículo. 2010. Orientadora: Martha Kaschny Borges. Dissertação (Mestrado em Educação) - Universidade do Estado de Santa Catarina, Florianópolis, 2010.

\section{SAUL, Ana Maria. Considerações a respeito do currículo. In: SEMINÁRIO} TENDÊNCIAS E PRIORIDADES DE CURRÍCULO NA REALIDADE BRASILEIRA. São Paulo: PUC-SP, 1985.

SENTANIN, Elisângela Ferreira. Viabilidade da implementação de computadores na primeira etapa da Educação Básica em uma rede pública municipal do interior de São Paulo. 2012. Orientador: Cláudio Benedito Gomide de Souza. Dissertação (Mestrado em Educação Escolar) - Faculdade de Ciências e Letras, Universidade Estadual Paulista, Araraquara, 2012.

SILVA, Ângela Carrancho da. Educação e tecnologia: entre o discurso e a prática. Ensaio: Avaliação e Políticas Públicas em Educação. Rio de Janeiro, v. 19, n. 72, p. 527-554, jul./set. 2011.

SILVA, Tomaz Tadeu da. O currículo como fetiche: a poética e a política do texto curricular. Belo Horizonte: Autêntica Editora, 2006.

SILVA, Josilda França da; SANTOS, Eliete Correia dos. O uso do celular na escola. In: SANTOS, Eliete Correia dos; SOUZA, Fábio Marques de; SOUSA, Kelly Cristina Trajano de (orgs.). Tecnologias educacionais e inovação: diálogos e experiências. Curitiba: Appris 2016. v. 2. p. 149-172.

VIEIRA PINTO, Álvaro. O conceito de tecnologia. Rio de Janeiro: Contraponto, 2005. v. 2.

\section{NOTA}

${ }^{1} \mathrm{O}$ presente artigo foi desenvolvido a partir de pesquisa de Mestrado defendida por Ana Claudia Pereira Rubio, no Programa de Pós-Graduação em Educação da Universidade Federal de Mato Grosso, em 2017, intitulada Tecnologias Digitais de Rede, integração curricular e práticas culturais de professores do final do Ensino Fundamental.

Enviado em: 08/07/2019

Aprovado em: 22/12/2019 